\title{
PREFERENSI PETANI TERHADAP KERAGAAN PADI VARIETAS UNGGUL BARU DI RAWA LEBAK TENGAHAN
}

\author{
Yanti Rina Darsani ${ }^{1}$ dan Anna Hairani*1 \\ ${ }^{1}$ Balai Penelitian Pertanian Lahan Rawa (Balittra) \\ Jalan Kebun Karet, Loktabat Utara, Banjarbaru Utara (70712) Kalimantan Selatan \\ e-mail: annagp8@gmail.com
}

\begin{abstract}
Introducing high yield varieties to farmers by demonstration plots is one of efforts to accelerate the adoption of these varieties. The objective of study was to determine the preferences of farmers on the characteristics of rice high yield varieties on medium freshwater swampland. The study was carried out on farmer's land at Hamayung village, Daha Utara subdistrict, Hulu Sungai Selatan regency in 2017. There were 20 selected farmers as respondents through simple random sampling. The data were (1) farmer characteristics and (2) rice morphology. It conducted on questionnaires and field observations. The obtained data were tabulated, grouped and analyzed descriptively. The results showed that (1) the most preferred performance of plants was plant age, panicle length, plant type, grain shape and plant height and (2) Mekongga, Inpari 30, Inpara 6, Inpari 9, Inpari 17, Ciherang and Inpara 8 were the preferred variety (from the most preferred order) varieties based on their agromorphology.
\end{abstract}

Keywords: farmer preferences, freshwater swampland, high yield varieties

\section{PENDAHULUAN}

Di Indonesia, luas lahan lebak diperkirakan 13,3 juta hektar, namun yang sesuai untuk pertanian 2,34 juta hektar (BBSDLP, 2014). Dari luas 13,3 juta hektar terdiri dari 4,2 juta hektar lebak dangkal, 6,1 juta hektar lahan lebak tengahan, dan 3,0 juta hektar lahan lebak dalam yang tersebar di pulau Sumatera, Kalimantan dan Irian Jaya (Khairullah et al, 2009). Luas lahan lebak yang sudah dibuka sampai tahun 2016 oleh pemerintah 615 ribu hektar dan oleh masyarakat 346 ribu hektar, sehingga jumlah yang baru dibuka 962 ribu hektar dan 1,37 juta hektar yang masih belum direklamasi (Subagio et al, 2015).

Fluktuasi genangan yang sukar diprediksi merupakan kendala pengelolaan lahan lebak untuk pertanian. Usaha diversifikasi pertanian di lahan rawa lebak telah lama dilaksanakan, namun hasil yang diperoleh selama ini masih rendah. Selain karena kendala fisiko-kimia lahan, rendahnya hasil juga disebabkan oleh pemilihan dan penerapan teknologi yang masih belum mengacu pada kondisi spesifik lokasi dan sosial-budaya setempat.

Umumnya petani melakukan penanaman padi satu kali setahun pada musim kemarau menggunakan varietas unggul. Varietas unggul yang sama dapat digunakan petani untuk beberapa musim, hal ini menyebabkan varietas tersebut peka terhadap serangan hama penyakit dan produktivitas padi rendah. Disamping itu persepsi petani terhadap penggunaan varietas unggul baru tergolong kurang baik, terutama pada hal penyediaan dan pengaplikasiannya di 
lapangan, meskipun pada dasarnya petani mengetahui dan memahami akan keuntungan dari penggunaan benih unggul baru tersebut (Hendrawati et al, 2014).

Untuk meningkatkan produksi padi di lahan lebak tengahan, perlu diintroduksikan varietas unggul baru yang adaptif, potensi hasil tinggi dan mutu hasil sesuai dengan preferensi petani. Teknologi varietas lebih aman dan ramah lingkungan serta harganya terjangkau petani (Mugiono et al, 2010). Lebih lanjut Ruskandar et al (2009) menyebutkan bahwa komponen inovasi teknologi yang diadopsi petani adalah varietas unggul. Badan Litbang Pertanian untuk periode 2000-2010 telah menghasilkan varietas unggul baru (VUB) padi terdiri dari 45 varietas non hibrida padi sawah, 17 varietas hibrida padi sawah, 2 varietas ketan dan 7 varietas padi gogo dan 7 varietas padi rawa (Suprihatno et al, 2011), meskipun demikian tidak semua varietas yang dihasilkan adaptif di lahan rawa. Varietas Inpara 1 sampai varietas 5 menunjukkan adaptasi dan hasil yang cukup tinggi, tetapi Inpara 1, 2 dan 3 lebih baik dibandingkan varietas Inpara 5 di lahan rawa lebak (Djufry dan Kasim, 2015; Helmi, 2015). Varietas Inpara 5 sangat rentan terhadap keracunan besi dan penyakit blas, sehingga tidak disarankan untuk dikembangkan di lahan rawa pasang surut (Koesrini et al, 2014). Selanjutnya Soemantri et al (2015) menyatakan bahwa varietas Inpari 10, Inpari 14 dan Ciherang memiliki potensi dikembangkan di daerah rawa lebak karena disukai petani terutama beras dan tekstur nasi pulen.

Petani tidak mudah mengganti varietas yang biasa ditanam kecuali varietas tersebut memiliki pemasaran dan adaptif di lokasi mereka. Pemilihan varietas oleh petani ditentukan oleh faktor eksternal seperti pasar, kelembagaan, kebijakan dan lingkungan (Irwan, 2013). Oleh karena itu perlu pengenalan melalui demonstrasi plot sehingga petani dapat melihat langsung keunggulan varietas tersebut. Lebih lanjut menurut Puspadi et al (2011) yang perlu dilakukan adalah pengenalan dan pengembangan serta penyebaran varietas unggul baru seperti penyampaian deskripsi varietas dan identifikasi kesukaan petani terhadap benih padi varietas unggul baru. Menurut Rohaeni et al (2012) biasanya pemilihan varietas berdasarkan pada sifat agronomis tanaman seperti tinggi tanaman dan jumlah anakan. Tingkat kesukaan petani terhadap varietas sangat penting diketahui, hal ini sebagai umpan balik bagi peneliti pemulia padi. Tujuan penelitian untuk mengetahui preferensi petani terhadap karakteristik varietas padi unggul di lahan rawa lebak tengahan.

\section{METODE PENELITIAN}

Penelitian dilakukan di lahan petani dalam bentuk demontrasi plot (10 varietas) dan metode survei di lahan rawa lebak tengahan di Desa Hamayung, Kecamatan Daha Utara, Kabupaten Hulu Sungai Selatan, Propinsi Kalimantan Selatan pada tahun 2017. Jumlah sampel sebanyak 20 orang yang dipilih secara acak sederhana. Data yang dikumpulkan meliputi karakteristik petani, tingkat preferensi petani terhadap 10 varietas yang ditanam dengan ukuran petak $9 \times 4$ $\mathrm{m}$ per varietas.

Penilaian petani terhadap tipe tanaman meliputi bentuk tanaman (tegak, agak tegak, dan menyebar dalam rumpun), tinggi tanaman, dan jumlah anakan produktif. Penilaian terhadap mutu gabah diamati bentuk/ukuran gabah (panjang/ramping, bulat atau sedang) dan warna gabah (bernas/mulus, keseragaman warna). 
Metode pengumpulan data menggunakan kuesioner sederhana agar responden mudah memahami dan mudah menjawab. Kuesioner dibuat dengan skala ordinal dengan pilihan jawaban responden, sangat suka, suka, cukup suka, tidak suka dan sangat tidak suka.

Metode analisis. Data yang telah diperoleh ditabulasi kemudian dianalisis menggunakan teknik skoring terhadap tingkat preferensi petani terhadap varietas (Tabel 1).

Tabel 1. Kategori tingkat preferensi petani di lahan rawa lebak tengahan

\begin{tabular}{ccccc}
\hline $\begin{array}{c}\text { Interval skor } \\
(\boldsymbol{\%})\end{array}$ & Preferensi & $\begin{array}{c}\text { Bobot } \\
(\boldsymbol{\%})\end{array}$ & $\begin{array}{c}\text { Jumlah petani } \\
(\mathbf{o r g})\end{array}$ & $\begin{array}{c}\text { Nilai skor } \\
(\boldsymbol{\%})\end{array}$ \\
\hline $84,01-100$ & Sangat suka & 20 & $\mathrm{n}$ & $\mathrm{n} \times$ bobot \\
$68,01-84$ & Suka & 20 & $\mathrm{n}$ & $\mathrm{n} \times$ bobot \\
$52,01-68$ & Cukup suka & 20 & $\mathrm{n}$ & $\mathrm{n} \times$ bobot \\
$36,01-52$ & Tidak suka & 20 & $\mathrm{n}$ & $\mathrm{n} \times$ bobot \\
$20-36$ & Sangat tidak suka & 20 & $\mathrm{n}$ & $\mathrm{n} \times$ bobot \\
\hline
\end{tabular}

Sumber: Rina dan Koesrini (2018)

Nilai skor yaitu bobot dikali jumlah petani untuk setiap varietas. Preferensi total dari setiap varietas merupakan skor rata-rata dari semua karakter yang dimiliki varietas tersebut. Jika nilai tertinggi berarti varietas tersebut paling disukai. Preferensi petani terhadap karakter varietas adalah rata-rata semua nilai skor untuk semua varietas yang diuji pada karakter yang sama. Jika nilai rata-rata karakter paling tinggi berarti karakter yang paling disukai. Data preferensi petani didistribusikan pada kelas yang berbeda. Pemberian skor menggunakan skala Likert berjenjang lima. Pernyataan preferensi responden dinyatakan dengan lima kelompok yaitu $1=$ sangat tidak suka, $2=$ tidak suka, $3=$ cukup suka, $4=$ suka, dan $5=$ sangat suka. Kelas-kelas tersebut memiliki interval yang besarnya ditentukan melalui rumus interval kelas. Nilai skor dinyatakan dalam bentuk persentase (Nasution dan Barizi, 1988 dalam Rina dan Koesrini, 2016; Suharyanto dan Kariada, 2011) dengan rumus:

$$
\text { Panjang interval }=\frac{\% \text { Skor tertinggi }-\% \text { skor terendah }}{\text { Jumlah interval kelas }}
$$

\section{HASIL DAN PEMBAHASAN}

\section{Karakteristik Petani}

Karakteristik petani Desa Hamayung disajikan pada Tabel 2. Umur petani rata-rata 46,9 tahun dengan kisaran 33 - 72 tahun. Sedangkan tingkat pendidikan rata-rata 7,3 tahun dengan kisaran 6-12 tahun. Tingkat pendidikan berada antara sekolah dasar hingga sekolah menengah pertama menunjukkan bahwa petani sudah melek huruf. Pengalaman bertani petani rata-rata 22 tahun, dapat dikatakan sudah cukup lama sehingga dari aspek pemahaman terhadap karakteristik lahan lebak sudah cukup. Terbatasnya ketersediaan sarana fisik menyebabkan petani tidak dapat mengatur air sehingga berdampak pada pelaksanaan indeks pertanaman. 
Tabel 2. Karakteristik petani di lahan rawa lebak tengahan Desa Hamayung, Kecamatan Daha Utara, 2017

\begin{tabular}{clcc}
\hline No. & Uraian & Rata-rata & Kisaran \\
\hline 1. & Umur (tahun) & 46.9 & $33-72$ \\
2. & Pendidikan (tahun) & 7,3 & $6-12$ \\
3. & Pengalaman bertani (tahun) & 22 & $5-35$ \\
4. & Tenaga kerja tersedia (HOK/KK/th) & 613,5 & $330-1200$ \\
5. & Luas lahan milik (ha/KK) & 0,425 & $0,18-0,57$ \\
6. & Luas lahan garapan (ha/KK) & 0,405 & $0,18-0,57$ \\
\hline
\end{tabular}

Sumber: data primer diolah, 2017

Ketersediaan tenaga kerja petani rata-rata $613 \mathrm{HOK} / \mathrm{KK} / \mathrm{TH}$ berkisar $300-1200$ HOK/KK/TH. Tenaga kerja petani digunakan untuk bertanam padi, sayuran dan mencari ikan. Pemilikan lahan oleh petani adalah 0,4 ha/KK dan digarap 95,3\% dari luas lahan yang dimiliki. Berdasarkan luas lahan yang dimiliki dan bertanam padi sekali setahun maka sulit bagi petani untuk meningkatan pendapatan. Melalui sistem surjan di lahan rawa lebak tengahan, petani dapat menanam sayuran yang bernilai tinggi seperti cabai besar, jagung, mentimun sehingga dapat menambah penghasilan.

\section{Preferensi Petani Terhadap Agromorfologi Varietas Padi Unggul}

Preferensi petani terhadap morfologi tanaman seperti tipe tanaman, umur tanaman, tinggi tanaman, jumlah anakan produktif, panjang malai, serta ketahanan terhadap hama dan penyakit dari 10 varietas yang diuji disajikan pada Tabel 3.

\section{Tipe Tanaman}

Keragaan tipe tanaman berkaitan dengan daya adaptasinya di lahan rawa lebak seperti kebanjiran dan kekeringan. Tipe tanaman juga berkaitan dengan penampilan tanaman tumbuh tegak atau serak. Padi unggul varietas inpara pada umumnya dirakit dari tetua dengan tipe tanaman dan daun berdiri tegak. Tipe ini mengikuti penetrasi dan distribusi cahaya lebih merata dibanding tipe tumbuh serak. Menurut Murchie et al (2002) dalam Koesrini et al (2017) melaporkan bahwa fotosintesa tanaman dengan daun tegak 20\% lebih tinggi dibandingkan kanopi daun terkulai pada kondisi indeks luas daun tinggi. Tabel 3 menunjukkan bahwa preferensi petani terhadap tipe tanaman saat vegetatif memperlihatkan dari sepuluh varietas yang ditanam, petani sangat suka pada varietas Mekongga dan suka pada varietas Inpara 6, 8, Inpari 9, 17, 30 dan Ciherang dan cukup suka pada varietas Inpara 7, 9, dan Inpari 20. Tipe tanaman tegak dan nampak kokoh disukai petani karena adaptif dengan lahan rawa lebak. Varietas Inpari 10, Inpari 14 dan Ciherang berpotensi dikembangkan di daerah rawa lebak karena disukai petani terutama beras dan tekstur nasi pulen (Soemantri et al, 2015). Selanjutnya varietas Inpara 3, 4, 6, 8, dan 9 memiliki hasil yang cukup tinggi dan adaptif di lahan rawa pasang surut (Koesrini et al, 2017) sedangkan hasil Inpara 6 (5,96 t/ha), Inpara 7 (6,34 t/ha), Inpara 8 (6,37 t/ha) Inpara 9 (3,07 t/ha), Inpari 9 (3,69 t/ha), Inpari 17 (5,63 t/ha), Inpari 20 (4,99 t/ha), Inpari 30 (4,70 t/ha), Mekongga (5,73 t/ha) dan Ciherang (6,42 t/ha) (Hairani et al, 
2017). Inpari merupakan inbrida padi untuk sawah irigasi. Rata-rata hasil Inpari pada lahan sawah irigasi dari seluruh provinsi: Inpari 9, Inpari 17, Inpari 20 dan Inpari 30 masing-masing sebesar 5,05 t/ha, 6,94 t/ha, 6,72 t/ha dan 6,66 t/ha (Sasmita et al, 2015).

Tabel 3. Preferensi petani terhadap morfologi tanaman varietas unggul di lahan lebak tengahan Desa Hamayung, Kecamatan Daha Utara, 2017

\begin{tabular}{|c|c|c|c|c|c|c|c|c|c|c|c|c|}
\hline \multirow{2}{*}{ Varietas } & \multicolumn{2}{|c|}{$\begin{array}{l}\text { Tipe } \\
\text { Tanaman }\end{array}$} & \multicolumn{2}{|c|}{$\begin{array}{l}\text { Tinggi } \\
\text { Tanaman }\end{array}$} & \multicolumn{2}{|c|}{$\begin{array}{l}\text { Jumlah } \\
\text { Anakan }\end{array}$} & \multicolumn{2}{|c|}{$\begin{array}{l}\text { Panjang } \\
\text { Malai }\end{array}$} & \multicolumn{2}{|c|}{$\begin{array}{l}\text { Bentuk } \\
\text { gabah }\end{array}$} & \multicolumn{2}{|c|}{$\begin{array}{l}\text { Warna } \\
\text { gabah }\end{array}$} \\
\hline & $\begin{array}{l}\text { Skor } \\
(\%)\end{array}$ & Kat & $\begin{array}{l}\text { Skor } \\
(\%)\end{array}$ & Kat & $\begin{array}{l}\text { Skor } \\
(\%)\end{array}$ & Kat & $\begin{array}{l}\text { Skor } \\
(\%)\end{array}$ & Kat & $\begin{array}{l}\text { Skor } \\
(\%)\end{array}$ & Kat & $\begin{array}{l}\text { Skor } \\
(\%)\end{array}$ & Kat \\
\hline Inpara 6 & 76,0 & $\mathrm{~s}$ & 78,0 & $\mathrm{~s}$ & 74,0 & $\mathrm{~s}$ & 74,0 & $\mathrm{~s}$ & 78.0 & $\mathrm{~s}$ & 70.0 & $\mathrm{~s}$ \\
\hline Inpara 7 & 66,0 & $\mathrm{cs}$ & 64,0 & $\mathrm{cs}$ & 65,0 & $\mathrm{cs}$ & 64,0 & $\mathrm{cs}$ & 72,0 & $\mathrm{~s}$ & 72,0 & $\mathrm{~s}$ \\
\hline Inpara 8 & 76,0 & $\mathrm{~s}$ & 78,0 & $\mathrm{~s}$ & 62,0 & $\mathrm{cs}$ & 74,0 & $\mathrm{~s}$ & 80,0 & $\mathrm{~s}$ & 68,0 & $\mathrm{cs}$ \\
\hline Inpara 9 & 66,0 & $\mathrm{cs}$ & 68,0 & $\mathrm{cs}$ & 72,0 & $\mathrm{~s}$ & 72,0 & $\mathrm{~s}$ & 70,0 & $\mathrm{~s}$ & 65,0 & cs \\
\hline Inpari 9 & 76,0 & $\mathrm{~s}$ & 74,0 & $\mathrm{~s}$ & 77,0 & $\mathrm{~s}$ & 70,0 & $\mathrm{~s}$ & 75,0 & $\mathrm{~s}$ & 71,0 & $\mathrm{~s}$ \\
\hline Inpari 17 & 71,0 & $\mathrm{~s}$ & 65,0 & $\mathrm{cs}$ & 71,0 & $\mathrm{~s}$ & 79,0 & $\mathrm{~s}$ & 72,0 & $\mathrm{~s}$ & 76,0 & $\mathrm{~s}$ \\
\hline Inpari 20 & 62,0 & $\mathrm{cs}$ & 57,0 & $\mathrm{cs}$ & 68,0 & $\mathrm{cs}$ & 69,0 & $\mathrm{cs}$ & 61,0 & $\mathrm{cs}$ & 63,0 & cs \\
\hline Inpari 30 & 83,0 & $\mathrm{~s}$ & 80,0 & $\mathrm{~s}$ & 72,0 & $\mathrm{~s}$ & 80,0 & $\mathrm{~s}$ & 75,0 & $\mathrm{~s}$ & 79,0 & $\mathrm{~s}$ \\
\hline Mekongga & 89,0 & ss & 86,0 & ss & 76,0 & $\mathrm{~s}$ & 91,0 & ss & 81,0 & $\mathrm{~s}$ & 81,0 & $\mathrm{~s}$ \\
\hline Ciherang & 69,0 & $\mathrm{~s}$ & 71,0 & $\mathrm{~s}$ & 70,0 & $\mathrm{~s}$ & 72,0 & $\mathrm{~s}$ & 72,0 & $\mathrm{~s}$ & 69,0 & $\mathrm{~s}$ \\
\hline
\end{tabular}

Sumber : data primer diolah, 2017

Ket: Kat= Kategori $:$ skor $52,01-68 \%=$ cukup suka $(\mathrm{cs}), 68,01-84 \%=$ suka $(s), 84,01-100 \%=$ sangat suka (ss)

\section{Postur tanaman}

Postur padi yang tinggi kurang diminati petani karena lebih mudah rebah (Diptaningsari, 2013). Tinggi tanaman merupakan salah satu kriteria seleksi pada tanaman padi, namun dengan postur tanaman yang tinggi tidak menjamin tingkat produktivitasnya (Asaad dan Warda, 2010). Tujuh puluh lima persen dari petani lebih menyukai tanaman padi dengan ketinggian sedang (Prayoga et al, 2018). Menurut IRRI (2014), kriteria tinggi tanaman tergolong rendah, sedang dan tinggi apabila tingginya masing-masing adalah $<110,110-130 \mathrm{~cm}$, dan $>130 \mathrm{~cm}$. Penilaian petani terhadap tinggi tanaman 10 varietas padi yang diuji, petani sangat menyukai tinggi tanaman varietas Mekongga, menyukai varietas Inpara 6, 8, Inpari 9, 30 dan Ciherang. Petani menyukai varietas tersebut karena tinggi tanaman sedang $(<110 \mathrm{~cm})$, batang kokoh dan kuat sehingga saat melakukan panen lebih mudah dibandingkan yang lebih pendek maupun terlalu tinggi. Tinggi tanaman varietas Inpara $6(99 \mathrm{~cm})$, Inpara $8(115,3 \mathrm{~cm})$ dan Inpari $9(113 \mathrm{~cm})$, Inpari $30(101 \mathrm{~cm})$ (BB Padi, 2016; Jamil et al, 2016). Tanaman yang sedang sampai tinggi, sangat cocok untuk lahan-lahan sawah pasang surut yang genangan airnya cukup dalam (Khairullah et al, 2007). Selanjutnya Rachmawati dan Retnaningrum (2013) melaporkan bahwa 
tinggi tanaman padi relatif lebih tinggi pada perlakuan genangan dibanding pada perlakuan tanpa genangan.

\section{Jumlah Anakan}

Petani pada umumnya menyukai tanaman padi dengan jumlah anakan banyak karena dianggap mampu menghasilkan gabah yang banyak. Jumlah anakan yang banyak dapat berpengaruh terhadap terhadap kompetisi inter spesies akan ketersediaan cahaya, $\mathrm{CO}_{2}, \mathrm{O}_{2}$, air, unsur hara, dan ruang untuk tumbuh sehingga jumlah anakan yang banyak berpengaruh terhadap produktivitas tanaman padi (Gani, 2003 dan Abdullah dalam Prayoga et al, 2018). Hasil penelitian menunjukkan bahwa preferensi petani terhadap jumlah anakan dikategorikan umumnya sangat suka terhadap varietas Mekongga, suka terhadap Inpara 6, 9, Inpari 9, 17, 30, Ciherang dan Mekongga dan cukup suka pada jumlah anakan varietas Inpara 7, 8 dan Inpari 20. Varietas-varietas tersebut menurut petani memiliki jumlah anakan produktif berkisar 10 20 batang/rumpun. Menurut Suprihatno et al. (2010) dan Jamil et al (2016), rata-rata jumlah anakan produktif masing-masing varietas tersebut adalah anakan produktif 13 batang (Inpara 6), 16-22 batang (Inpari 9),13-16 batang (Mekongga) dan 14-17 batang (Ciherang). Menurut Soemantri et al (2015) varietas Inpari 10, Inpari 14 dan Ciherang berpotensi dikembangkan di daerah rawa lebak karena disukai petani terutama beras dan tekstur nasi pulen.

\section{Panjang Malai}

Panjang malai merupakan komponen penting dalam menentukan produksi. Semakin panjang malai maka peluang terbentuknya jumlah gabah per malai semakin besar dan merupakan parameter pendukung untuk potensi hasil (Utama dan Haryoko, 2009; Waluyo et al 2015)). Namun menurut Dwi et al (2009) kerapatan gabah lebih berperan penting dibanding panjang malai.

Berdasarkan hasil analisis preferensi petani terhadap panjang malai dapat dikategorikan petani sangat suka terhadap varietas Mekongga, suka terhadap varietas Inpara 6, 8, 9, Inpari 9, 17, 30 dan Ciherang. Petani menyukai panjang malai varietas-varietas tersebut, karena menyerupai varietas lokal yang umumnya memiliki malai yang panjang antara $21-30 \mathrm{~cm}$ (sedang). Tipe malai dengan panjang yang sedang akan mampu memaksimalkan hasil karena tidak menutupi juga tidak terlalu terbuka. Malai yang termasuk dalam kategori malai panjang (> $30 \mathrm{~cm})$, sedang $(21-30 \mathrm{~cm})$ dan pendek $(<20 \mathrm{~cm})$ (Diptaningsari, 2013)

\section{Bentuk dan Warna gabah}

Bentuk gabah merupakan salah satu yang dipertimbangkan petani hal ini karena bentuk gabah yang panjang dan ramping memiliki harga yang lebih tinggi dibandingkan yang bulat. Preferensi petani terhadap bentuk gabah dikategorikan suka terhadap semua varietas yang diuji kecuali Inpari 20. Bentuk gabah varietas Inpara 9, Inpari 9, Inpari 17, Inpari 30 umumnya ramping panjang sedangkan Inpari 20 bentuknya ramping tapi kurang panjang sehingga terlihat lebih besar dibanding Inpari 9, 17 dan 30. Petani menyukai bentuk gabah yang panjang dan ramping mirip varietas lokal. Selain varietas Inpari yang memiliki bentuk gabah panjang dan ramping adalah Inpara 7 dan Inpara 9, Mekongga dan Ciherang (BB Padi 2016). Selanjutnya petani menyukai tanaman padi ukuran gabah yang panjang dan lebar (Prayoga et al, 2018). Hasil uji preferensi Ningsih dan Khairatun (2013) di lahan rawa pasang surut juga menunjukkan bahwa $75 \%$ petani memilih varietas Inpara yang berbentuk gabah panjang ramping dan $60 \%$ menyukai rasa nasi pera. Petani lahan pasang surut etnis Jawa dan Banjar 
menyukai bentuk gabah varietas Margasari yang menyerupai varietas lokal panjang dan ramping (Rina dan Koesrini, 2018).

Preferensi petani lahan lebak terhadap warna gabah dikategorikan suka terhadap varietas yang diuji yakni Inpara 6, Inpara 7, Inpari 9, Inpari 17, Inpari 30, Mekongga dan Ciherang kecuali Inpara, 8, 9, dan Inpari 20. Hal yang sama petani etnis Jawa dan banjar sama-sama menyukai warna gabah varietas Inpara 3, 5, 6, 8, 9 dan Margasari (Rina dan Koesrini, 2018). Petani menyukai warna gabah varietas tersebut kuning bersih, tidak kusam, dan seragam serta tidak ada bercak. Warna gabah varietas Mekongga, Inpari 9, 17, 30, Ciherang berwarna kuning bersih dan kuning (Jamil et al, 2016).

\section{Preferensi Petani Terhadap Ketahanan Hama Penyakit dan Umur}

Preferensi petani terhadap ketahanan varietas terhadap hama penyakit dan umur tanaman disajikan pada Tabel 4. Penilaian petani terhadap ketahanan serangan hama penyakit dari 10 varietas yang diuji ternyata cukup suka terhadap semua varietas. Menurut petani hampir semua varietas tidak tahan terhadap serangan hama dan penyakit, meskipun Inpari 17, 20, 30 agak tahan terhadap wereng batang coklat (Jamil et al, 2016). Selanjutnya hasil penelitian di lahan rawa lebak Kabupaten Banyu asin menunjukkan varietas Inpari 30 lebih tahan terhadap blas (Guwat et al, 2017).

Tabel 4. Preferensi petani terhadap ketahanan hama penyakit dan umur tanaman varietas unggul di lahan lebak tengahan, Desa Hamayung, Kecamatan Daha Utara, 2017

\begin{tabular}{llcccc}
\hline \multirow{2}{*}{ No } & Uraian & \multicolumn{2}{c}{ Ketahanan Hama Penyakit } & \multicolumn{2}{c}{ Umur Tanaman } \\
\cline { 3 - 6 } & & Skor (\%) & Kategori & Skor (\%) & Kategori \\
\hline 1. & Inpara 6 & 64,0 & Cukup suka & 71.0 & Suka \\
2. & Inpara 7 & 53,0 & Cukup suka & 69,0 & Suka \\
3. & Inpara 8 & 54,0 & Cukup suka & 69,0 & Suka \\
4. & Inpara 9 & 58,0 & Cukup suka & 72,0 & Suka \\
5. & Inpari 9 & 63,0 & Cukup suka & 74,0 & Suka \\
6. & Inpari 17 & 64,0 & Cukup suka & 80,0 & Suka \\
7. & Inpari 20 & 50,0 & Cukup suka & 70,0 & Suka \\
8. & Inpari 30 & 65,0 & Cukup suka & 77,0 & Suka \\
9. & Mekongga & 62,0 & Cukup suka & 89,0 & Sangat suka \\
10. & Ciherang & 62,0 & Cukup suka & 80,0 & Suka \\
\hline
\end{tabular}

Sumber : data primer, 2017

Ket: Kategori : skor 52,01-68\% = cukup suka, 68,01-84\% = suka, 84,01-100\% = sangat suka 
Penilaian petani terhadap umur tanaman 10 varietas menunjukkan bahwa petani sangat menyukai varietas Mekongga, suka pada umur varietas Inpara 6, 7, 8, 9, Inpari 9, 17, 20, 30 dan Ciherang. Varietas Inpara 6, 7, 8, 9 berumur $114-117$ hari (Suprihatno et al, 2011) sedangkan Mekongga, Inpari 9, 17, 20, 30 dan ciherang adalah 111-125 hari (Jamil et al, 2016). Untuk bertanam padi di lahan rawa lebak tengahan dibutuhkan umur varietas padi yang genjah karena masa kering di lahan sawah lebak cukup pendek (Juli- September/Oktober).

\section{Preferensi Petani Terhadap Agromorpologi Varietas Unggul}

Preferensi petani terhadap karakteristik varietas padi unggul seperti tipe tanaman, tinggi tanaman, jumlah anakan produktif dan panjang malai, umur tanaman, ketahanan terhadap hama penyakit, bentuk gabah dan warga gabah dari 10 varietas yang diuji pada Tabel 5 . Tabel 5 menunjukkan bahwa preferensi petani terhadap karakteristik 10 varietas unggul di lahan lebak tengahan, terdapat 7 varietas yang disukai petani yaitu Inpara 6, Inpara 8, Inpari 9, Inpari 17, Inpari 30, Mekongga dan Ciherang. Varietas Inpara 7, Inpara 9 dan Inpari 20 cukup disukai. Berdasarkan jumlah nilai skor secara keseluruhan, maka varietas yang paling disukai secara berturut-turut adalah Mekongga, Inpari 30, Inpara 6, Inpari 9, Inpari 17, Ciherang dan Inpara 8. Varietas Mekongga paling disukai karena selain sudah lebih adaptif, juga varietas Mekongga lebih berat dibanding varietas lainnya kecuali varietas Ciherang. Berat 1000 biji varietas Mekongga (28 gram), sedang varietas Inpari 9 (23,3 gr), Inpari 17 (25 gr), Inpari 20 (25,6 gr), Inpari 30 (27gr) (bbpadi.litbang.pertanian.go.id/indek/php/varietas/inbrida-padi-sawah-irigasiinpari).

Tabel 5. Preferensi petani terhadap keragaan tanaman varietas unggul di lahan
lebak tengahan Desa Hamayung Utara, Kecamatan Daha Utara, 2017

\begin{tabular}{lccccccccccl}
\hline Varietas & TT & TGT & JA & PM & UR & HP & BG & WG & $\begin{array}{c}\text { Total } \\
\text { skor }\end{array}$ & $\begin{array}{c}\text { Rerata } \\
\text { skor }\end{array}$ & Kategori \\
\hline Inpara 6 & 76,0 & 78,0 & 74,0 & 74,0 & 71.0 & 64,0 & 78.0 & 70.0 & 585 & 73,12 & Suka \\
Inpara 7 & 66,0 & 64,0 & 65,0 & 64,0 & 69,0 & 53,0 & 72,0 & 72,0 & 525 & 65,62 & Cukup suka \\
Inpara 8 & 76,0 & 78,0 & 62,0 & 74,0 & 69,0 & 54,0 & 80,0 & 68,0 & 561 & 70,12 & Suka \\
Inpara 9 & 74,0 & 68,0 & 72,0 & 72,0 & 72,0 & 58,0 & 70,0 & 65,0 & 551 & 68,87 & Suka \\
Inpari 9 & 76,0 & 74,0 & 77,0 & 70,0 & 74,0 & 63,0 & 75,0 & 71,0 & 580 & 72,50 & Suka \\
Inpari 17 & 71,0 & 65,0 & 71,0 & 79,0 & 80,0 & 64,0 & 72,0 & 76,0 & 578 & 72,25 & Suka \\
Inpari 20 & 62,0 & 57,0 & 68,0 & 69,0 & 70,0 & 50,0 & 61,0 & 63,0 & 500 & 62,50 & Cukup suka \\
Inpari 30 & 83,0 & 80,0 & 72,0 & 80,0 & 77,0 & 65,0 & 75,0 & 79,0 & 611 & 76,37 & Suka \\
Mekongga & 89,0 & 86,0 & 76,0 & 91,0 & 89,0 & 62,0 & 81,0 & 81,0 & 655 & 81,87 & Suka \\
Ciherang & 69,0 & 71,0 & 70,0 & 72,0 & 80,0 & 62,0 & 72,0 & 69,0 & 564 & 70,50 & Suka \\
\hline Rerata & $\mathbf{7 4 , 2}$ & $\mathbf{7 2 , 1 ,}$ & $\mathbf{7 0 , 7}$ & $\mathbf{7 4 , 5}$ & $\mathbf{7 5 , 1}$ & $\mathbf{5 9 , 5}$ & $\mathbf{7 3 , 6}$ & $\mathbf{7 1 , 4}$ & $\mathbf{5 7 1}$ & $\mathbf{7 1 , 3 7}$ & \\
\hline
\end{tabular}

Sumber : data primer, 2017 
Ket: TT=Tipe Tanaman, TGT=Tinggi Tanaman, JA=Jumlah Anakan, PM=Panjang Malai, UR=Umur Tanaman, HP=Ketahanan Hama Penyakit, BG=Bentuk Gabah, WG=Warna Gabah

Kategori : skor $52,01-68 \%=$ cukup suka, $68,01-84 \%=$ suka, $84,01-100 \%=$ sangat suka

\section{KESIMPULAN}

Semua parameter keragaan tanaman dari 10 varietas yang diuji disukai oleh petani kecuali terhadap parameter ketahanan serangan hama dan penyakit. Urutan kesukaan dari yang paling banyak disukai terhadap keragaan tanaman adalah umur tanaman, panjang malai, tipe tanaman, bentuk gabah dan tinggi tanaman. Sedangkan berdasarkan karakteristik varietas, yang disukai petani adalah Mekongga, Inpari 30, Inpara 6, Inpari 9, Inpari 17, Ciherang dan Inpara 8.

\section{DAFTAR PUSTAKA}

Asaad, M dan Warda. (2010). Keragaan Beberapa Galur Harapan Padi Sawah di Kabupaten Sidrap, Sulawesi Selatan. Dalam Supriatno, B. et al., (Penyunting). Prosiding Seminar Ilmiah Hasil Penelitian Padi Nasional. Balai Besar Penelitian Tanaman Padi Badan Litbang Pertanian Kementerian Pertanian, pp 11-22.

Balai Besar Penelitian dan Pengembangan Sumberdaya Lahan Pertanian (BBSDLP). (2014). Luas, Penyebaran dan Potensi Sumberdaya Lahan Pertanian Nasional. Badan Penelitian dan Pengembangan Pertanian.

Balai Besar Penelitian Tanaman Padi (BB Padi). (2016). Deskripsi Varietas. Diunduh 2 Oktober 2017, dari http://bbpadi.litbang.pertanian.go.id

Bbpadi.litbang.pertanian.go.id/index.php/varietas/ inbrida-padi-sawah-irigasi-inpari. Deskripsi Varietas Inbrida Padi Irigasi. Diunduh 27 Desember 2017.

Djufry, F. dan A. Kasim. (2015). Uji Adaptasi Varietas Unggul Baru Padi Rawa pada Lahan Sawah Bukaan Baru di Kabupaten Marauke Provinsi Papua. Jurnal Agrotan 1(1):99109.

Dwi, I.S., A.C. Trilaksana, T. Koesoemaningtyas, dan B.S. Purwoko. (2009). Karakterisasi Galur Haploid Ganda Hasil Kultur Antara Padi. Buletin Plasma Nutfah 15(1): 1-12

Diptaningsari, D. (2013). Analisis Keragaman Karakter Agronomis Dan Stabilitas Galur Harapan Padi Gogo Turunan Padi Lokal Pulau Buru Hasil Kutur Antera. Disertasi Program Pascasarjana. Institut Pertanian Bogor. Bogor (tidak dipublikasikan).

Guwat, S., Waluyo dan P. Sasmita. (2017). Produksi dan Usahatani Padi Varietas Unggul Baru di Lahan Rawa Lebak Kabupaten Banyuasin Sumatera Selatan. Jurnal Penelitian Terapan Vol 17(3): 176-180.

Helmi. (2015). Peningkatan Produktivitas Padi Lahan Rawa Lebak Melalui Penggunaan Varietas Unggul Padi Rawa. Jurnal Pertanian Tropik 2 (2):78-92

Hendrawati, E., E, Yurisnthae dan Radian. (2014). Analisis Persepsi Petani Dalam menggunakan Benih Padi Unggul di Kecamatan Muara Pawan Kabupaten Ketapang. Jurnal Social Economic of Agriculture 3(1): 53-57. 
Hairani, A., Khairil Anwar, M. Saleh, Maulia Aries S. (2017). Penelitian Perbaikan Teknologi Peningkatan produktivitas Lahan Lebak Untuk Meningkatkan Produksi Padi dan Cabai. Laporan Akhir Rencana Penelitian Tim Peneliti Tahun Anggaran 2017. Balai Penelitian Pertanian Lahan Rawa. BBSDLP.

International Rice Reseacrh Institute (IRRI). (2014). Standard Evaluation System for Rice. International Rice Research Institute. Manila Philippines. 37p.

Irwan. (2013). Faktor Penentu dan Keputusan Petani Dalam Memilih Varietas Benih Kedelai di Kabupaten Pidie. Jurnal Agrisep Vol (14) No 1. 2013. Jurusan Sosial Ekonomi Pertanian Fakultas Pertanian Universitas Syiah Kuala Banda Aceh.

Jamil, A., M.J. Mejaya, R.H. Praptana, N.A. Subekti, M. Aqil, A. Musaddad dan F. Putri. (2016). Deskripsi Varietas Unggul Tanaman Pangan 2010-2016. Puslitbang Pertanian. $152 \mathrm{p}$

Khairullah I, Mawardi, dan Sarwani M. (2007). Karakteristik Dan Pengelolaan Lahan Rawa: 7. Sumber Daya Hayati Pertanian Lahan Rawa. Balai Besar Penelitian dan Pengembangan Sumberdaya Lahan Pertanian, Bogor.

Khairullah I., M. Saleh, dan Mawardi. (2009). Penampilan Beberapa galur WAR 115-1-2-4-24-B-B-4 di Lahan Lebak Tengahan Kalimantan Selatan. Prosiding Seminar Nasional Padi tanggal 23-24 Juli 2008. Balai Besar Penelitian Tanaman Padi. Badan Litbang Pertanian. Sukamandi. Inovasi Teknologi Padi Mengantisipasi Perubahan Iklim Global Mendukung Ketahanan Pangan. Buku I. pp 127-2138.

Koesrini, E. William, dan I. Khairullah. (2014). Varietas Padi Adaptif Lahan Rawa Pasang Surut. Dalam: Nursyamsi et al., (eds.). Teknologi Inovasi Lahan Rawa Pasang Surut Mendukung Kedaulatan Pangan Nasional. IAARD Press, Badan Litbang Pertanian. pp 97-118

Koesrini, M. Saleh dan S. Nurzakiah. (2017). Adaptabilitas Varietas Inpara di Lahan Rawa Pasang Surut Tipe Luapan B pada Musim Kemarau. Jurnal Agron. Indonesia 45(2):117123.

Mugiono, Sherly Rahayu, dan Jeany P. Mandang. (2010). Penggunaan Teknik Mutasi Radiasi untuk Perbaikan Bentuk dan Umur Padi Varietas Superwin. Prosiding Seminar Nasional Hasil Penelitian Padi 2009. Buku 1, 20 Oktober 2009. Balai Besar Penelitian Tanaman Padi. Badan Litbang Pertanian Sukamandi. pp 161-170

Ningsih, D.N. dan N. Khairatun. (2013). Preferensi Konsumen Terhadap Padi Inpara Dan Penampilan Pertumbuhan Di Lahan Rawa Kabupaten Barito Kuala. Prosiding Seminar Nasional Menggagas Kebangkitan Komoditas Unggulan Lokal Pertanian dan Kelautan. Madura, Juni 2013. Faperta Universitas Trunojoyo. pp 172-177.

Prayoga, M., K.N. Rostini, M.R. Setiawati, T. Simarmata, S.Stoeber dan K. Adinata. (2018). Preferensi Petani Terhadap Keragaan Padi (Oryza sativa) unggul untuk Lahan Sawah di Wilayah Pengandaran dan Cilacap. Jurnal Kultivasi Maret 2018. Vol 17(1):523-530.

Puspadi, K., S. Untung, Pridiminggo dan L. Hadiawat. (2011). Akselerasi Adopsi Varietas Unggul Baru Padi Melalui Model Industri Perbenihan Padi Rakyat Di Nusa Tenggara Barat. Prosiding Seminar Nasional Hasil Penelitian Sosial Ekonomi Pertanian. Penguatan Sosial Ekonomi Menuju Kesejahteraan Masyarakat. UGM, Yogyakarta.

Rachmawati dan Retnaningrum. (2013). Pengaruh Tinggi dan Lama Penggenangan Terhadap Pertumbuhan Padi Kultivar Sintanur dan Dinamika Populasi Rhizobakteri Pemfiksasi 
Nitrogen Non Simbiosis, Bionatura. Jurnal Ilmu-Ilmu Hayati dan Fisik, Vol 15(2):112125.

Rina, Y. dan Koesrini. (2016). Tingkat adopsi varietas Inpara dan Margasari di lahan rawa pasang surut. Jurnal Agros 18 (1):65-80.

Rina, Y. dan Koesrini. (2018). Preferensi Petani Terhadap Karakter Beberapa Varietas Unggul Padi Lahan Rawa Pasang Surut. Jurnal Penelitian Pertanian Vol 2(2): 85-94

Rohaeni, W.R., A. Sinaga dan M.I. Ishaq. (2012). Preferensi Responden Terhadap Keragaan Tanaman dan Kualitas Produk Beberapa Varietas Unggul Baru Padi. Informatika Pertanian 21(2): 107-115.

Ruskandar, A., S. Wahyuni, U.S. Nugraha, dan Widyantoro. (2009). Preferensi Petani Terhadap Beberapa Varietas Unggul Padi (Studi Kasus Di Kecamatan Kedung Tuban, Kabupaten Blora). Dalam Anischan Gani et al., (eds). Prosiding Seminar Nasional Padi 2008: Inovasi Teknologi Padi Mengantivasi Perubahan Iklim Global Mendukung Ketahanan pangan. Balai Besar Penelitian Tanaman padi.

Sasmita, P., A. Guswara, dan Idrus Hasmi. (2015). Keragaman Produktivitas Varietas Unggul Baru pada Berbagai daerah Target Pengembangan. Dalam Ahmad Dewi Setiyawan et al. (eds). Prosiding Seminar Nasional Bioversitas "Strategi Pengelolaan Sumber Daya hayati Nusantara untuk Mewujudkan Ketahanan Pangan Secara Berkelanjutan, Universitas Negeri Surakarta.

Soemantri, R. Utami dan Syahri. (2015). Preferensi Petani di Lahan Rawa Lebak Sumatera Selatan Terhadap Varietas Unggul baru (VUB) Hasil Litbang Pertanian (Studi Kasus: Poktan Sinar Sakti Desa Lubuk Sakti Kecamatan Indralaya Kabupaten Ogan Ilir). Jurnal Lahan Sub Optimal Oktober 2015. Vol 4, (2): 154-162.

Subagio, H., M. Noor, W. A. Yusuf, dan I. Khairullah. (2015). Perspektif Pertanian Lahan Rawa: Mendukung Kedaulatan Pangan. Badan Litbang Pertanian. Kementerian Pertanian. IAARD Press, Jakarta. Dicetak oleh Gadjah Mada University Press, Yogyakarta. $108 \mathrm{p}$.

Suharyanto dan I.K. Kariada. (2011). Kajian adopsi penerapan teknologi pupuk organik kascing di daerah sentra produksi sayuran Kabupaten Tabanan. Jurnal Pengkajian dan Pengembangan Teknologi Pertanian 14 (1): 28-39.

Suprihatno, B., A.A. Daradjat, Satoto, dan Baehaki. (2010). Deskripsi Varietas Padi. Balai Besar Penelitian tanaman Padi. Sukamandi.113 p.

Suprihatno B, Daradjat A.A, Satoto, Suwarno, Lubis E, Baehaki S.E., Sudir S.D., Indrasari I.P., Wardana, dan Mejana M.J. (2011). Deskripsi Varietas Padi (Edisi Revisi). Balai Besar Penelitian Tanaman Padi. Badan Penelitian dan Pengembangan Pertanian.

Utama, M.Z.H. dan W. Haryoko. (2009). Pengujian Empat Varietas Padi Unggul pada Sawah Gambut Bukaan Baru di Kabupaten Padang pariaman. Jurnal Akta Agrosia 12(1): 5661

Waluyo, Y. Hutapea dan Suparwoto. (2015). Pengkajian Varietas Unggul Baru Padi (Inpari) di Lahan Sawah Tadah Hujan, Kabupaten Ogan Komering Ilir Sumatera Selatan. Prosiding Seminar Nasional Hasil Penelitian Padi 2014. Buku 2, 19 Agustus 2014. Balai Besar Penelitian Tanaman Padi. Badan Litbang Pertanian. Sukamandi. pp 631-642. 